Acta Technologica Agriculturae 3

Nitra, Slovaca Universitas Agriculturae Nitriae, 2014, pp. 57-60

\title{
EFFECT OF TYPE OF CUTTING TIPS ON CUTTING FORCES IN TURNING
}

\author{
Pavel POLÁK*, Ján ŽITŇANSKÝ, Martina FERANCOVÁ \\ Slovak University of Agriculture in Nitra, Slovak Republic
}

\begin{abstract}
The aim of this article is to demonstrate the effect of cutting materials and geometry of cutting tips on cutting forces in turning as well as the quality and precision of machined surface. The experiment focuses on measuring cutting forces when turning a sample of steel 11523 at a constant feed rate and cut depth and at varying speeds of a spindle. Measurements were made using exchangeable cutting tips of different types. The results will be evaluated in terms of the impact of different characteristics of cutting tips and variable spindle speeds.
\end{abstract}

Keywords: turning, cutting materials, cutting tips, cutting forces

The production process is a role of the management system consisting in determining the optimum, most economical or productive conditions for implementing a particular manufacturing operation. The management system of production process should ensure that the given process complies with its intended use without undesirable failures or risks (Petrík et al., 2009; Vysočanská et al., 2009).

The machining of materials is a working process by which a semi-finished product obtains the required shape and dimensions of a part by removing the material from the surface layer. The most widespread method of machining is cutting in which material is removed in the form of chips by mutual interaction of the tool and workpiece. Based on a long-term development of cutting materials, creating a completely new cutting material cannot be expected in the near future; therefore, the research of leading manufacturers of tools and cutting materials is primarily aimed at improving existing materials, specifying their optimal use, and exactly defining fields of their application.

In the cutting process, the cutting part of the tool is exposed to high temperatures, mechanical stress, friction, vibrations and sudden thermal and mechanical shocks. Therefore, the measurement and examination of material behaviour under these conditions is an integral part of the research and development of cutting materials.

The aim is to monitor and evaluate changes in cutting forces between the cutting tool and workpiece in turning, induced by different properties of individual cutting tips, and also monitoring changes in these characteristics in three different speeds of the lathe spindle.

\section{Material and methods}

We have focused on studying the effect of cutting material (exchangeable cutting tip) and chip former geometry on cutting forces. In order to monitor the effect of one factor only, measurement conditions were necessary to be ensured so as to eliminate other factors that could influence the change in these parameters. We used the cutting tips of the same type (DNMG 150608), of various cutting materials, and with several chip former types. When assessing the effect of cutting material, we compared only those tips the only distinguishing feature of which was cutting material. We proceeded in the same way when assessing the effect of the geometry of cutting tips chip former. Furthermore, we were also interested in how individual cutting tips behave at different speeds; therefore, our measurements were conducted at three different speeds, i.e. $n_{1}=710 \mathrm{rpm}^{-1}$, $n_{2}=1,400 \mathrm{rpm}^{-1}$ and $n_{3}=2,240 \mathrm{rpm}^{-1}$. Other cutting conditions were held constant, i.e. cut depth $a_{p}=1 \mathrm{~mm}$ and feed rate $f=0.1 \mathrm{~mm}^{-1}$. Steel 11523 belonging to the group P was used as a material sample. The cutting tips used for our measurements are intended for machining this group of materials.

\section{Characteristics of sample}

Four samples of the same shape, size and material were used for the experiment.

The dimensions of the sample are shown in Figure 1. The sample was clamped using a three-jaw chuck. Since we needed to avoid vibration, it was necessary to shore the

Table 1 Mechanical properties and chemical composition of steel 11523

\begin{tabular}{|c|c|c|c|c|c|c|c|}
\hline \multicolumn{8}{|c|}{ Chemical composition in \% 11523} \\
\hline C & Si & S & Mn & $\mathbf{P}$ & $\mathbf{N}$ & yield strength, $\boldsymbol{R}_{e}$ in $\mathbf{M P a}$ & tensile strength, $\boldsymbol{R}_{m}$ in $\mathbf{M P a}$ \\
\hline \hline 0.2 & 0.55 & 0.04 & 1.6 & 0.04 & 0.009 & 345 & $490-630$ \\
\hline
\end{tabular}


Table 2 Parameters of holder PDJNR 2525 M15

\begin{tabular}{|c|c|c|c|c|c|c|c|}
\hline $\boldsymbol{h}=\mathbf{h} \mathbf{1}$ in $\mathbf{~ m m}$ & B in $\mathbf{~ m m}$ & $\boldsymbol{F}$ in $\mathbf{~ m m}$ & $\boldsymbol{I}_{\mathbf{1}}$ in $\mathbf{~} \mathbf{m}$ & $\boldsymbol{I}_{2}$ max in $\mathbf{~ m m}$ & Rake angle $\gamma_{\mathbf{0}}$ in $^{\circ}$ & Angle of cutting edge $\lambda_{\boldsymbol{s}}$ in $^{\circ}$ & Weight in $\mathbf{~ k g}$ \\
\hline \hline 25 & 25 & 32 & 150 & 40 & -6 & -6 & 0.68 \\
\hline
\end{tabular}

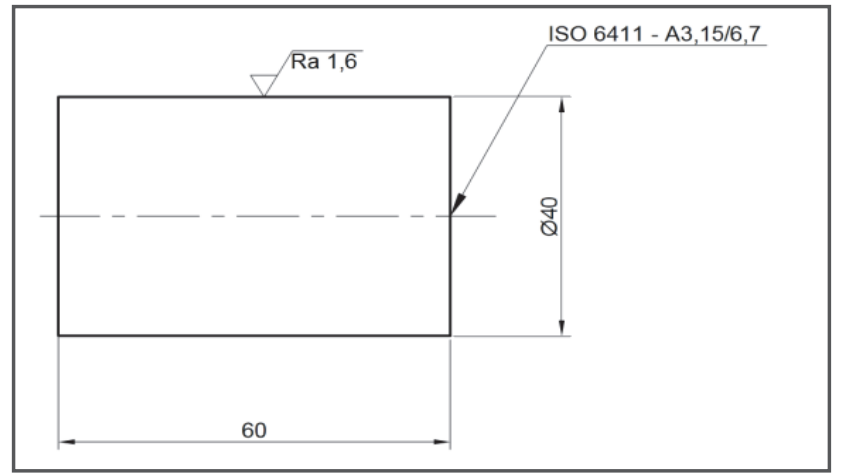

Figure $1 \quad$ Drawing of test sample

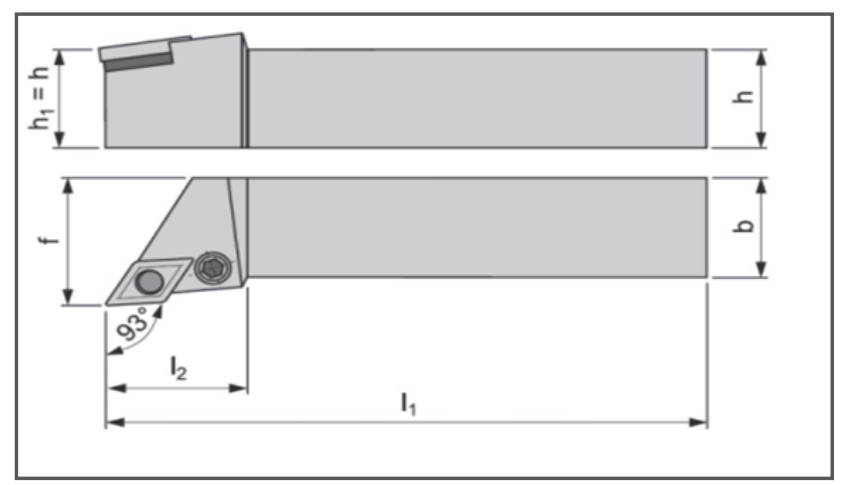

Figure 2

PDJNR knife for external turning

sample up by a tailstock. For that reason, it was necessary to drill a centring hole.

\section{Characteristics of holder}

A knife holder (Figure 2) for external turning by Pramet Tools, s. r. o. (private limited company), with designation PDJNR 2525 M15.

\section{Characteristics of cutting tips}

\section{Shape and dimensions}

There were used exchangeable cutting tips by Pramet Tools, s. r. o., designated as DNMG 150608.

Dimensions of DNMG 150608: $/=15.5 \mathrm{~mm}, d=12.7 \mathrm{~mm}$, $d_{1}=5.16 \mathrm{~mm}, s=6.35 \mathrm{~mm}, r_{\varepsilon}=0.8 \mathrm{~mm}$.

\section{Results and discussion}

\section{Measurement of cutting forces}

Cutting forces were measured using a strain-gauge method, by a specially adapted holder of the turning knife for exchangeable cutting tips with attached strain gauges. Strain gauges mounted on the holder are deformed due to cutting forces generated during turning. These deformations were evaluated based on the size of current, using the measuring device Mikrotechna M 1000. The measured values of electric current (Table 3 ) were converted to cutting forces $(N)$ using

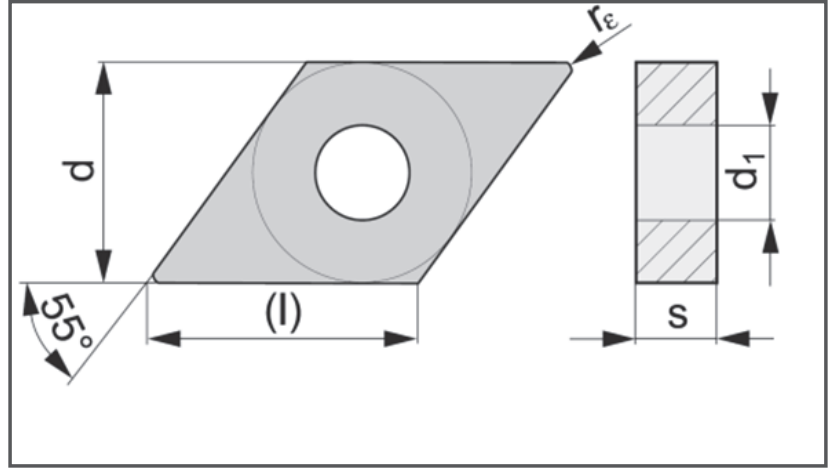

Figure 3 Dimensions of exchangeable cutting tip of type DNMG 150608

a calibration table. There were used nine types of cutting tips, and for each tip, measurements were performed at three different speeds, i.e. $n_{1}=710 \mathrm{rpm}^{-1}, n_{2}=1,400 \mathrm{rpm}^{-1}$ and $n_{3}=2,240 \mathrm{rpm}^{-1}$. Feed rate and cut depth remained unchanged during the measurement, and the same material sample was turned.

Table 3 Calibration table

\begin{tabular}{|l||c|c|c|c|c|c|}
\hline $\boldsymbol{F}$ in $\mathbf{N}$ & 120 & 240 & 360 & 480 & 600 & 720 \\
\hline $\boldsymbol{I}$ in $\mathbf{m A}$ & 6 & 12 & 18 & 24 & 30 & 60 \\
\hline
\end{tabular}

\section{Results of measuring cutting forces}

The measured results (table 4) were achieved in turning the same steel material samples $11523^{\text {rd }}$ At each cutting inserts have been replaced by three speeds, and $n_{1}=710 \mathrm{~min}^{-1}$, $n_{2}=1,400 \mathrm{~min}^{-1}$ and $n_{3}=2,240 \mathrm{~min}^{-1}$ while we wonder how they will change the values for each speed. Other cutting conditions were held constant, and the depth of cut $a_{p}=$ $1 \mathrm{~mm}$ and a feed rate $f=0.1 \mathrm{~mm}^{-1}$. In evaluating the results, we have also focused on assessing the impact of cutting material and type chipformer the measured quantities.

Table 4 Measured values of cutting forces

\begin{tabular}{|l|c||c|c|c|}
\hline \multicolumn{2}{|c||}{ Cutting tip DNMG 150608 } & \multicolumn{4}{c|}{ Cutting force in N } \\
\cline { 3 - 5 } \multicolumn{2}{|c||}{} & \multicolumn{3}{c|}{ Speed in rpm } \\
\hline Chip former & Material & $\mathbf{7 1 0}$ & $\mathbf{1 , 4 0 0}$ & $\mathbf{2 , 2 4 0}$ \\
\hline \hline M & 6615 & 440 & 260 & 240 \\
\hline M & 6610 & 440 & 260 & 240 \\
\hline R & 9230 & 480 & 280 & 240 \\
\hline F & 9230 & 480 & 280 & 240 \\
\hline M & 6630 & 480 & 280 & 260 \\
\hline R & 6630 & 480 & 320 & 280 \\
\hline R & 6640 & 560 & 320 & 280 \\
\hline SI & 6630 & 560 & 360 & 280 \\
\hline RM & 9210 & 560 & 360 & 320 \\
\hline
\end{tabular}




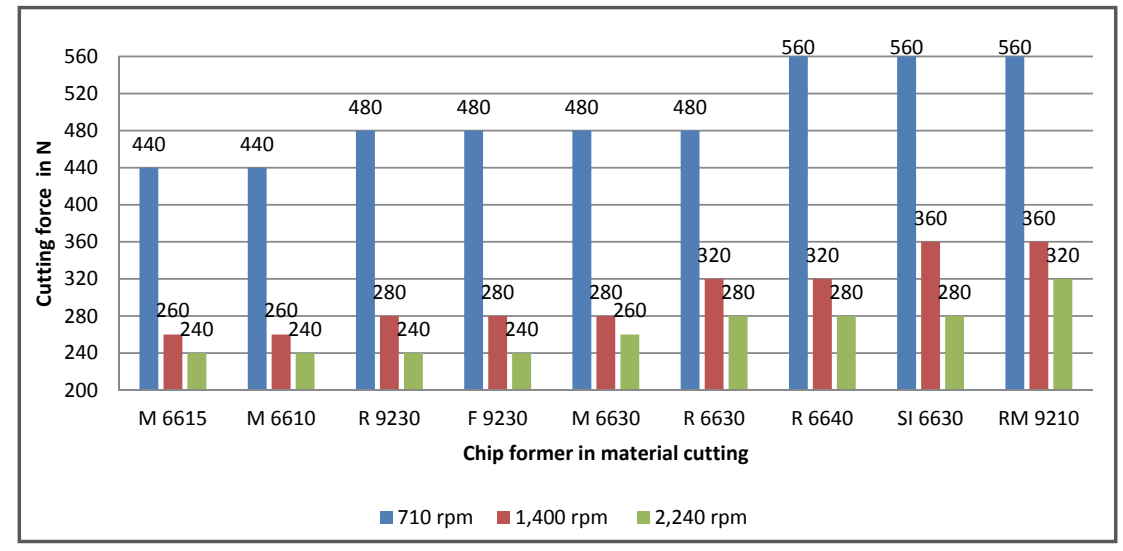

Figure 4 Effect of exchangeable cutting tip type on cutting forces

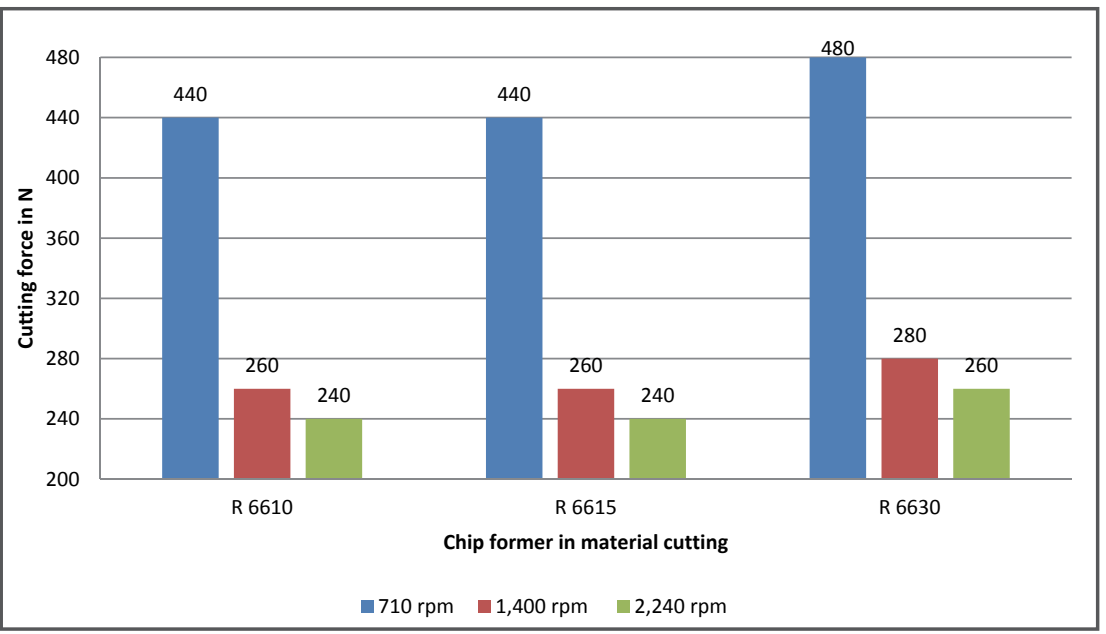

Figure 5 Effect of cutting material on cutting forces

Table 5 Comparison of cutting forces measured using exchangeable cutting tip with chipformer of type $M$

\begin{tabular}{|l|c||c|c|c|}
\hline \multicolumn{2}{|l||}{ Cutting tip DNMG 150608} & \multicolumn{3}{c|}{ Cutting force in N } \\
\cline { 2 - 5 } \multicolumn{1}{|l||}{ Chip former } & Material & $\mathbf{7 1 0}$ & $\mathbf{1 , 4 0 0}$ & $\mathbf{2 , 2 4 0}$ \\
\hline M & 6610 & 440 & 260 & 240 \\
\hline M & 6615 & 440 & 260 & 240 \\
\hline M & 6630 & 480 & 280 & 260 \\
\hline
\end{tabular}

Table 6

Comparison of cutting forces measured using exchangeable cutting tip with a chip former of type $R$

\begin{tabular}{|c|c|c|c|c|}
\hline \multirow{2}{*}{\multicolumn{2}{|c|}{ Cutting tip DNMG 150608}} & \multicolumn{3}{|c|}{ Cutting force $\mathrm{N}$} \\
\hline & & \multicolumn{3}{|c|}{ Speed in rpm } \\
\hline Chip former & Material & 710 & 1,400 & 2,240 \\
\hline $\mathbf{R}$ & 9230 & 480 & 280 & 240 \\
\hline $\mathbf{R}$ & 6630 & 480 & 320 & 280 \\
\hline $\mathbf{R}$ & 6640 & 560 & 320 & 280 \\
\hline
\end{tabular}

\section{Effect of cutting material on cutting forces}

When assessing the impact of cutting material (table 5) the cutting forces when we are comparing the values measured in the plates M-6610, M-6615 and M-6630 showed only slight changes.

Plates M-6610 and M-6615 achieved in all three the same speed and the lowest cutting forces. In the the plate M-6630 were measured at speed $n_{2}$ and $n_{3}$ values higher cutting forces of $20 \mathrm{~N}$ as the plates M-6610 and M-6615, and at the speed $n_{1}$ been measured value of cutting force of $40 \mathrm{~N}$ higher than the plates M-6610 and M-6615. Higher cutting forces in the material 6630 may result from the fact that the material 6630 is designed for high cutting speeds, while the materials 6610 and 6615 are designed for higher cutting speeds and therefore are anticipated to their superior properties.

In assessing the impact of cutting material for plates with $\mathrm{R}$ chipformer materials from 9230, 6630 and 6640 (Table 6) lowest value recorded material cutting force in 9230 all three speeds but at a speed $n_{1}$ reached the same value of the material 6630. Material 9230 is machinable material new generation designed for moderate and high cutting speeds, the material 6630 is the first medium cutting speeds and material 6640 is designed for low to medium cutting speeds. Based on the impact assessment of the cutting material of the cutting force can be concluded that cutting materials for higher cutting speeds with lower cutting forces at a given cutting conditions.

\section{Impact on the species chipformer cutting forces}

The impact assessment chipformer geometry of the cutting force measured values were compared at three plates of the same material as 6630 with chipformer type $M, R$ and $S I$.

From the measured values of the cutting force shows that the lowest value of the cutting force of the plate reached chipformer of $M$ having a facet and deducted a cutting edge at an angle of $10^{\circ}$, higher the cutting forces were measured at the R-chipformer, which also has a facet, but has a cutting edge withheld at an angle of $5^{\circ}$ and the highest cutting forces were at the plate with chipformer of $\mathrm{SI}$, without facet with rounded cutting edge. 


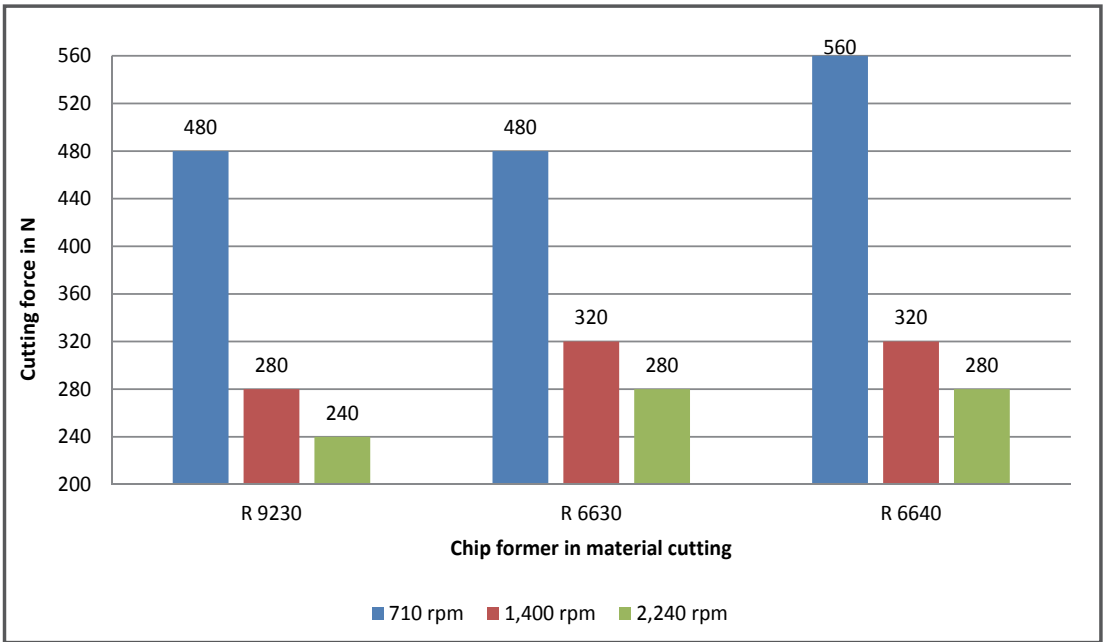

Figure 6 Effect of cutting material on cutting forces

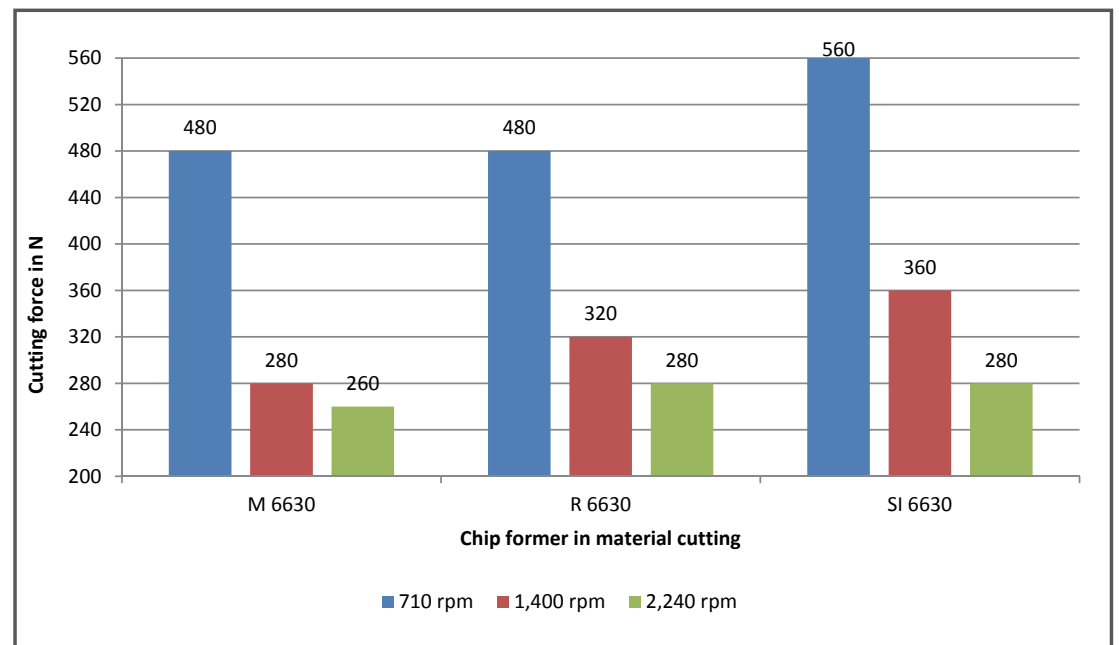

Figure 7 Effect of cutting material cutting forces

Table 7 Comparison of cutting force measured using VRD material 6630

\begin{tabular}{|l|c||c|c|c|}
\hline \multicolumn{2}{|c||}{ Cutting tool tips DNMG 150608 } & \multicolumn{3}{c|}{ Cutting force [N] } \\
\cline { 3 - 5 } & Material & $\mathbf{7 1 0}$ & $\mathbf{1 4 0 0}$ & $\mathbf{2 2 4 0}$ \\
\hline Chip former & 6630 & 480 & 280 & 260 \\
\hline \hline M & 6630 & 480 & 320 & 280 \\
\hline R & 6630 & 560 & 360 & 280 \\
\hline SI & \multicolumn{3}{|c|}{} \\
\hline
\end{tabular}

\section{Conclusion}

When measuring cutting forces, it was found that cutting forces are decreasing with increasing values of cutting speed. This phenomenon can be explained by the fact that cutting forces are increasing at low speeds due to intense friction between the tool face and chip. With increasing speed, the strength of workpiece material decreases and its plasticity increases, thus reducing cutting forces.

It has been found that the same cutting forces, or with slight differences and RM-9210 with the highest cutting forces recorded, diameters were less than $39 \mathrm{~mm}$, representing a negative deviation from the required diameter.

Based on the facts mentioned above, dimensional accuracy decreases with increasing cutting force, and diameter values are higher than the required size. When exceeding a certain value of cutting force, diameter values are lower than the required size. When assessing the effect of the type of cutting material and chip former on cutting forces and dimensional accuracy, there were recorded differences in measured values. When evaluating the results, one must not forget taking into account other important influencing factors, which could not be eliminated in our experiments, such factors being mainly the stiffness and condition of the lathe used, accuracy of measuring devices and ultimately the human factor, too.

\section{References}

BÁTORA, B. - VASILKO, K. 2000. Obrobené povrchy. Technologická dedičnost', funkčnost'. Trenčín :TU, 2000, 184 pp. ISBN 80-88914-19-1.

GELETA, V. 2010. Machining technology. Bratislava : STU, 2010, 165 pp. ISBN 978-80-227-3335-9.

JANÁČ, A. - LIPA, Z. - PETERKA, J. 2006. Teória obrábania. Bratislava : STU, 2006, 199 pp. ISBN 80-227-2347-9.

KREIDL, M. 2005. Měření teploty - senzory a měřicí obvody. Praha : Marten, 2005, 240 pp. ISBN 80-7300-145-4.

NESLUŠAN, M. 2009. Sústruženie kalených ocelí. Žilina : Edis, 2009, 253 pp. ISBN 978-80-554-104-1.

PETRÍK, M. - KOTUS, M. 2009. Automatizácia tlakového liatia vo výrobnom procese. In Bezpečnost' - kvalita - spol'ahlivost'. Košice :TU, 2009, pp. 173-177. ISBN 978-80-553-0137-2. VYSOČANSKÁ, M. - SKLENÁR, M. - PETRÍK, M. - KOTUS, M. 2009. Hodnotenie spôsobilosti meracieho zariadenia. In Najnovšie trendy $\mathrm{v}$ polnohospodárstve, $\mathrm{v}$ strojárstve a $v$ odpadovom hospodárstve. Nitra : SUA, 2009, pp. 327-332. ISBN 978-80-552-0208-2. ŽITNYANSKÝ, J. - ŽARNOVSKÝ, J. - KOVÁČ, I. 2012. Rezné materiály a ich vplyv na proces sústruženia. In Kvalita a spolahlivost' technických systémov. Nitra : SUA, 2012, pp. 181-185. ISBN 978-80-552-0798-8.

\section{Contact address:}

Ing. Pavel Polák, PhD., Slovak University of Agriculture in Nitra, Faculty of Engineering, Department of Quality and Engineering Technologies, Tr. Andreja Hlinku 2, 94976 Nitra, SR, e-mail: Pavel.Polak@uniag.sk 